\title{
CONSIDERING ON LIGHTNING ELECTRIC FIELDS IN PRESENCE OF GROUND REFLECTION AT NON-PERFECT GROUND
}

\author{
Mahdi Izadi $^{* *}$ - M. Z. A. Ab Kadir ${ }^{*}$ - Maryam Hajikhani ${ }^{* * *}$
}

\begin{abstract}
In this paper, general electric field expressions are proposed to consider the effect of channel base ground reflections and ground conductivity on the electric field components due to lightning. The proposed method can support different current models and functions directly in the time domain without the need to apply any extra conversions. The proposed method is applied on a sample of measured channel base current from triggered lightning experiment and the results are discussed accordingly. The results show that the ground reflection and ground conductivity can have an effect on the peak values of the electric fields whereby the electric field components have a great effect on the widely used coupling models.

K eyw ords: lightning, electromagnetic fields, ground conductivity, ground reflection factor
\end{abstract}

\section{INTRODUCTION}

The evaluation of electromagnetic fields due to lightning is an important issue in the consideration of protection for distribution lines versus lightning induced voltages [1-4]. Such fields are dependent on the lightning current parameters, channel parameters and the geometry of the observation point with respect to the lightning channel [5-9]. Several studies have been undertaken to estimate the electromagnetic fields due to lightning while these studies usually ignore the ground reflection due to the difference between the channel and ground impedances at the striking point [10-16]. Moreover, the ground conductivity has a direct effect on the value of the electromagnetic fields that is usually considered by a number of converter expressions in the frequency domain [5, 17-19]. In this paper, general electric field expressions are proposed to cover the effects of ground reflection and ground conductivity on the values of the electric fields due to a lightning channel directly in the time domain without the need to apply any extra conversions. The proposed method can support the widely used current functions and models and they can be combined with coupling models to evaluate the lightning induced voltage in the time domain. The basic assumptions in this study are listed as follows:

- the lightning channel is a vertical channel

- the ground surface is assumed to be flat

- the effect of lightning branches is ignored.

\section{RETURN STROKE CURRENT}

In this paper, the current wave shape at the channel base is simulated based on the sum of two Heidler functions as given by (1), [20-23]. On the other hand, the current wave shapes at different heights along the lightning channel can be expressed by the general form of the engineering model that is expressed by (2), [8, 24-27].

$$
\begin{array}{r}
I(0, t)=\frac{i_{01}}{\eta_{1}} \frac{\left(t / \tau_{11}\right)^{n_{1}}}{1+\left(t / \tau_{11}\right)^{n_{1}}} \exp \left(-t / \tau_{12}\right)+ \\
+\frac{i_{02}}{\eta_{2}} \frac{\left(t / \tau_{21}\right)^{n_{2}}}{1+\left(t / \tau_{21}\right)^{n_{2}}} \exp \left(-t / \tau_{22}\right) \\
i\left(z^{\prime}, t\right)=i\left(0, t-\frac{z}{v}\right) P\left(z^{\prime}\right) U\left(t-\frac{z^{\prime}}{v_{f}}\right)
\end{array}
$$

where $i(0, t)$ is the channel base current, $t$ is the time step, $i_{01}$ and $i_{02}$ are amplitudes of the channel base current, $\tau_{11}$ and $\tau_{12}$ are front time constants, $\tau_{21}$ and $\tau_{22}$ are decay-time constants, $n_{1}, n_{2}$ are exponent from interval $(2--10), z$ is temporary charge height along channel, $v$ is return stroke current velocity along channel, $v_{f}$ is return stroke current velocity along channel, $U\left(t-z^{\prime} / v_{f}\right)$ is the Heaviside function and

$$
\begin{gathered}
\eta_{1}=\exp \left[-\left(\tau_{11} / \tau_{12}\right)\left(n_{1} \tau_{12} / \tau_{11}\right)^{1 / n_{1}}\right] \\
\eta_{1}=\exp \left[-\left(\tau_{21} / \tau_{22}\right)\left(n_{2} \tau_{22} / \tau_{21}\right)^{1 / n_{2}}\right]
\end{gathered}
$$

Likewise, (2) can be extended to the case of the lightning channel with a ground reflection at the channel base

\footnotetext{
* Centre for Electromagnetic and Lightning Protection research, Faculty of Engineering, University Putra Malaysia, UPM, Serdang, Selangor 43400, Malaysia, ${ }^{* *}$ Department of Electrical, Firoozkooh Branch, Islamic Azad University, Firoozkooh, Iran, ${ }^{* * *}$ Aryaphase Company, Tehran, Iran, aryaphase@yahoo.com
} 


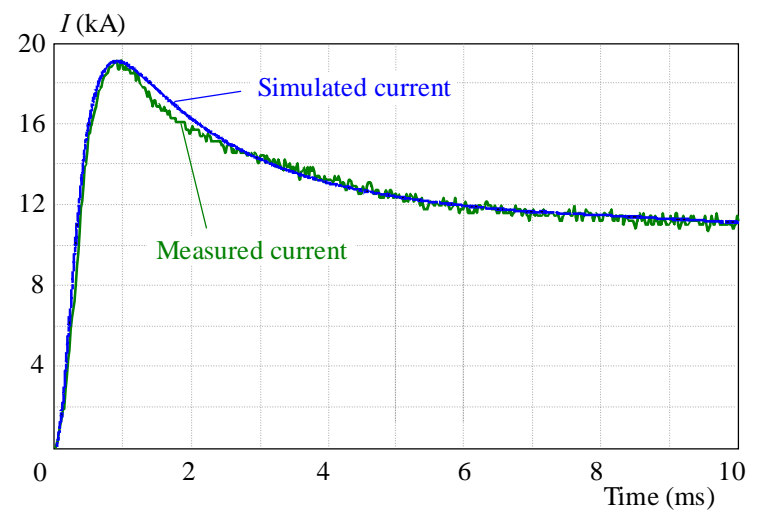

Fig. 1. Comparison between the simulated channel base current and the corresponding measured current

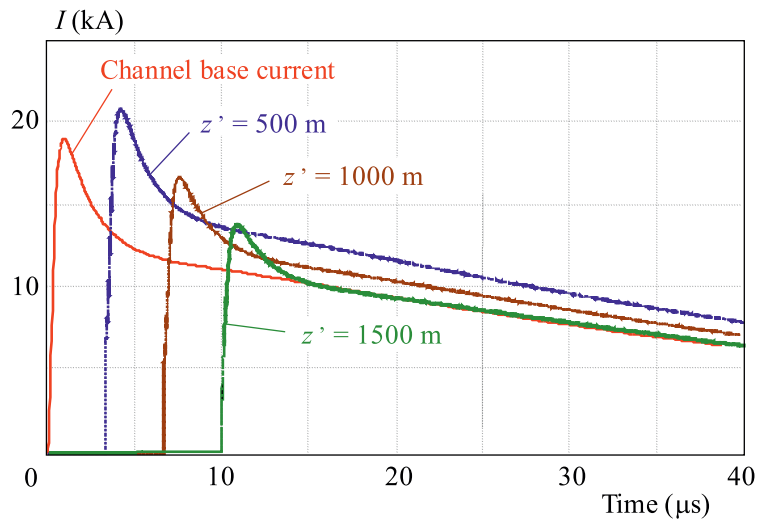

Fig. 3. The behavior of current wave shapes at different heights along lightning channel based on $\rho_{g}=0.4$

as given by equation (3) whereby the ground reflection is due to the difference between the channel and ground impedances at the connection point, [28]. Equation (3) shows that the current at different heights can be divided into two parts $i e$ the original current that is attenuated by the attenuation height dependent factor with a propagation velocity equal to $v_{f}$ and the reflected current with a propagation speed equal to $c$. These currents are controlled by the return stroke front velocity. Table 1, [9] describes the attenuation height dependent factor and return stroke current velocity for a number of widely used current models. It should be mentioned that the return stroke velocity is usually entered into the field calculations as a constant value between $c / 3$ to $2 c / 3$, [29].

$$
\begin{aligned}
& i_{g r}\left(z^{\prime}, t\right)= \\
& {\left[P\left(z^{\prime}\right) i\left(0, t-\frac{z^{\prime}}{v}\right)+\rho_{g} i\left(0, t-\frac{z^{\prime}}{c}\right)\right] U\left(t-\frac{z^{\prime}}{v_{f}}\right)}
\end{aligned}
$$

where $\rho_{g}$ is ground reflection coefficient equal to: $\left(z_{c h}-\right.$ $\left.z_{g}\right) /\left(z_{c h}+z_{g}\right), z_{c h}$ is the surge impedance of return stroke channel, $z_{g}$ is the ground impedance, $i_{g r}\left(z^{\prime}, t\right)$ is the return stoke current at different heights along channel in presence of ground reflection factor.

In this paper, a sample of a measured channel base current is used for the simulation of a channel base current based on the sum of two Heidler functions. The measured current is obtained from a triggered lightning experiment

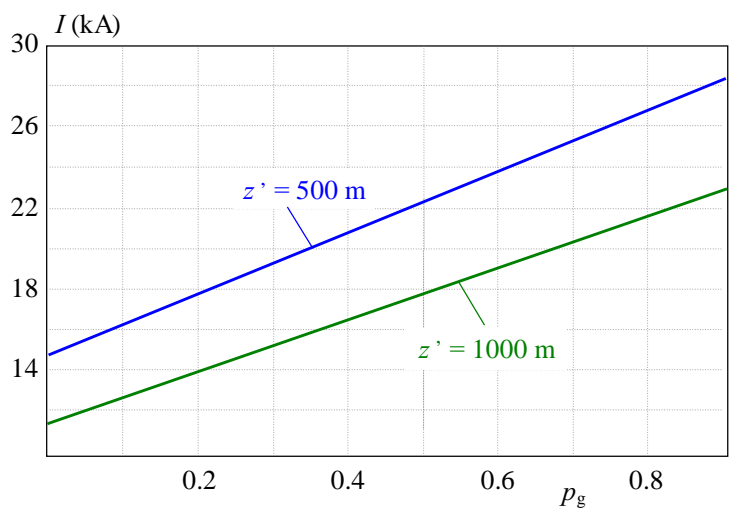

Fig. 2. The behavior of current peak against ground reflection changes at $z=500 \mathrm{~m}$ and $1000 \mathrm{~m}$ height along channel

and the evaluated current parameters are in Tab. 2. Figure 1 illustrates a comparison between the simulated and measured channel base currents which shows that the simulated current is in good agreement with the corresponding measured current.

Table 1. The coefficients for five current models based on equation (3) from [9]

\begin{tabular}{ccc}
\hline Model & $P\left(z^{\prime}\right)$ & $v$ \\
\hline BG & 1 & $\infty$ \\
TCS & 1 & $-c$ \\
TL & 1 & $v_{f}$ \\
MTLL & $1-\frac{z^{\prime}}{H_{c}}$ & $v_{f}$ \\
MTLE & $\exp \left(-\frac{z^{\prime}}{\lambda}\right)$ & $v_{f}$ \\
\hline
\end{tabular}

Moreover, in order to consider the effect of the ground reflection on the peak values of the return stroke current at different heights along a lightning channel, the behaviour of the current peaks at two different heights with respect to the surface of the ground versus different values of the ground reflection factors is illustrated in Fig. 2.

Table 2. The current parameters based on equation (1)

\begin{tabular}{cccccccc}
\hline$i_{01}$ & $i_{02}$ & $\tau_{11}$ & $\tau_{12}$ & $\tau_{21}$ & $\tau_{22}$ & $n_{1}$ & $n_{2}$ \\
$(\mathrm{kA})$ & $(\mathrm{kA})$ & $(\mu \mathrm{s})$ & $(\mu \mathrm{s})$ & $(\mu \mathrm{s})$ & $(\mu \mathrm{s})$ & $(-)$ & $(-)$ \\
\hline 17.76 & 10.38 & 0.42 & 1.7 & 2.52 & 49.67 & 2 & 2 \\
\hline
\end{tabular}

As shown in Fig. 2, the current peak has a direct relationship with the value of the ground reflection factor. Therefore, the ground reflection can indirectly have an effect on the electromagnetic fields due to lightning as explained in next section. It should be noted that the MTLE (Modified Transmission Line with Exponential decay model), [4] current model is used with typical values of $\lambda$ and $v_{f}$ equal to 2000 and $1.5 \times 10^{8} \mathrm{~m} / \mathrm{s}$, respectively. Moreover, the current wave shapes at four differ- 


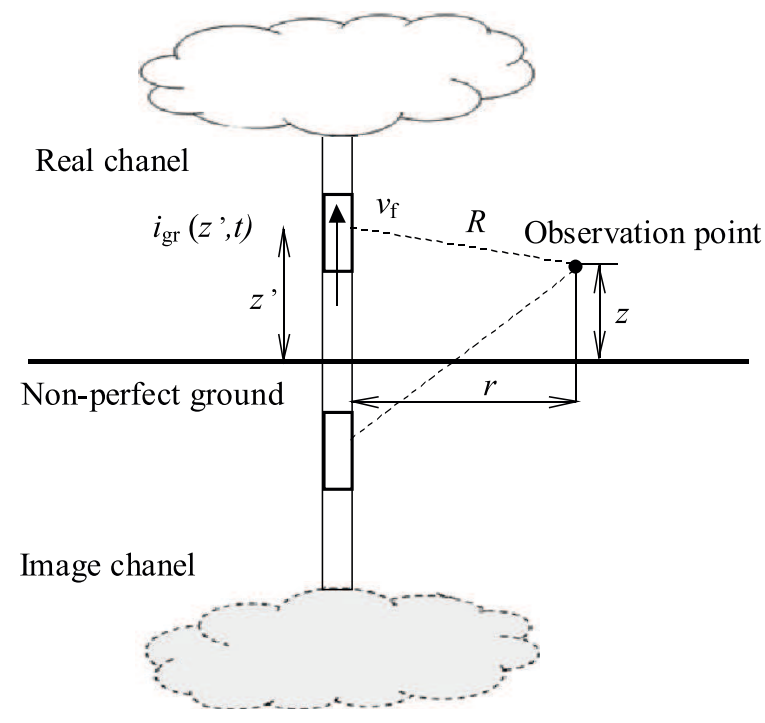

Fig. 4. The geometry of problem

ent heights along the lightning channel with a value of the reflection factor equal to 0.4 is illustrated in Fig. 3.

\section{LIGHTNING ELECTRIC FIELD EXPRESSIONS}

The electric fields associated with a lightning channel can be evaluated by equations (4) and (5) for vertical and horizontal field components respectively, whereby the geometry of the problem is shown in Figure 4 and the Dipole, Trapezoid and FDTD methods are applied[7, 9, 16, 30-31]. The electric field expressions consider the ground reflection factor at a striking point directly in the time domain while the perfect ground conductivity condition is set as a basic assumption.

$$
\begin{aligned}
& \boldsymbol{E}_{r}\left(t_{n}\right)=\boldsymbol{E}_{r}\left(t_{n-1}\right)+\Delta t \sum_{i=1}^{n} \sum_{m=1}^{k+1} a_{m} F_{i}\left(t_{n}, h_{m, i}\right) \\
& -a_{m}^{\prime} F_{i}\left(t_{n}, h_{m, i}^{\prime}\right) \\
& \boldsymbol{E}_{z}\left(t_{n}\right)=\boldsymbol{E}_{z}\left(t_{n-1}\right)+\Delta t \sum_{i=1}^{n} \sum_{m=1}^{k+1} a_{m} F_{i}\left(t_{n}, h_{m, i}\right) \\
& -a_{m}^{\prime} F_{i}\left(t_{n}, h_{m, i}^{\prime}\right)
\end{aligned}
$$

where $E_{r}(t) \equiv E_{r}(r, z, t)$ is the horizontal electric field in perfect ground conductivity condition, $z$ is height of observation point, $c$ is light speed in free space, $r$ is radial distance from lightning channel, $\beta=v / c, \chi=$ $\sqrt{1 /\left(1-\beta^{2}\right)}, t_{n}=\sqrt{r^{2}+z^{2}} / c+(n-1) \Delta t$, with $\Delta t=$ $t_{i}-t_{i-1}$ for $n=1,2, \ldots, n_{\max }$. and
$\Delta h_{i}=\left\{\begin{array}{l}\beta \chi^{2}\left[c \Delta t-\sqrt{\left(\beta c t_{i}-z\right)^{2}+(r / \chi)^{2}}+\right. \\ \left.\quad+\sqrt{\left(\beta c t_{i-1}-z\right)^{2}+(r / \chi)^{2}}\right] \\ \beta \chi^{2}\left[-\left(\beta z-c t_{i}\right)-\sqrt{\left(\beta c t_{i-1}-z\right)^{2}+(r / \chi)^{2}}\right] \\ \text { for } i=1\end{array}\right.$

$\Delta h_{i}^{\prime}=\left\{\begin{array}{l}-\beta \chi^{2}\left[c \Delta t+\sqrt{\left(\beta c t_{i}+z\right)^{2}+(r / \chi)^{2}}\right. \\ \left.\quad-\sqrt{\left(\beta c t_{i-1}+z\right)^{2}+(r / \chi)^{2}}\right] \\ \beta \chi^{2}\left[-\left(\beta z-c t_{i}\right)-\sqrt{\left(\beta c t_{i-1}+z\right)^{2}+(r / \chi)^{2}}\right] \\ \text { for } i=1\end{array}\right.$ $h_{m, i}\left\{\begin{array}{l}\frac{(m-1) \Delta h_{i}}{k}+h_{m=k+1 . i-1} \\ \frac{(m-1) \Delta h_{i}}{k} \quad \text { for } i=1\end{array}\right.$ $h_{m, i}^{\prime}\left\{\begin{array}{l}\frac{(m-1) \Delta h_{i}^{\prime}}{k}+h_{m=k+1 . i-1}^{\prime} \\ \frac{(m-1) \Delta h_{i}^{\prime}}{k} \quad \text { for } i=1\end{array}\right.$ $R_{m}=\sqrt{r^{2}+\left(z-h_{m, i}\right)^{2}}$

$$
\begin{aligned}
F_{i}\left(r, z, t_{n}, h_{m, i}\right) & =\frac{r\left(z-h_{m, i}\right)}{4 \pi \varepsilon_{0} R_{m}^{3}}\left(\frac{3}{R_{m}^{2}} i_{g r}+\right. \\
& \left.+\frac{3}{c R_{m}} \frac{\partial i_{g r}}{\partial t}+\frac{1}{c^{2}} \frac{\partial^{2} i_{g r}}{\partial^{2} t}\right)
\end{aligned}
$$

$$
\begin{array}{r}
F_{i}^{\prime}\left(r, z, t_{n}, h_{m, i}\right)=\frac{1}{4 \pi \varepsilon_{0} R_{m}^{3}}\left(\frac{2\left(z-h_{m, i}\right)^{2}-r^{2}}{R_{m}^{2}} i_{g r}+\right. \\
\left.+\frac{2\left(z-h_{m, i}\right)^{2}-r^{2}}{c R_{m}} \frac{\partial i_{g r}}{\partial t}-\frac{r^{2}}{c^{2}} \frac{\partial^{2} i_{g r}}{\partial^{2} t}\right)
\end{array}
$$




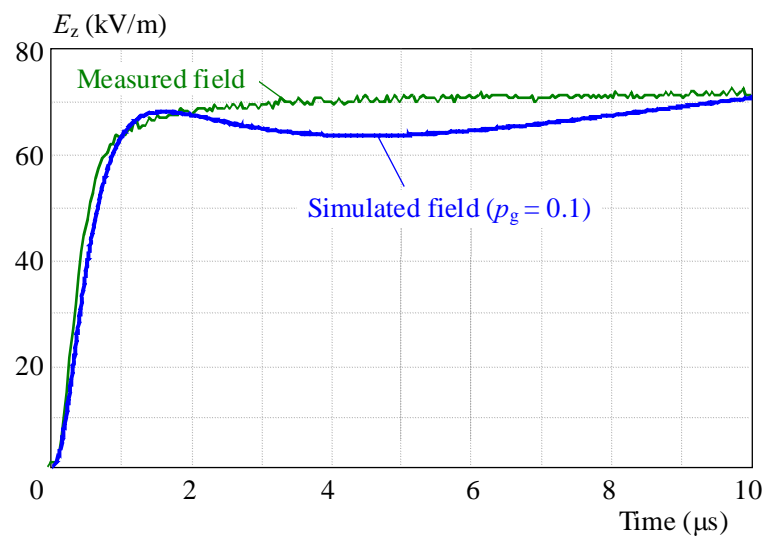

Fig. 5. Comparison of simulated and measured vertical electric fields at perfect ground condition $r=30, z=0$, and $\rho_{g}=0.1$

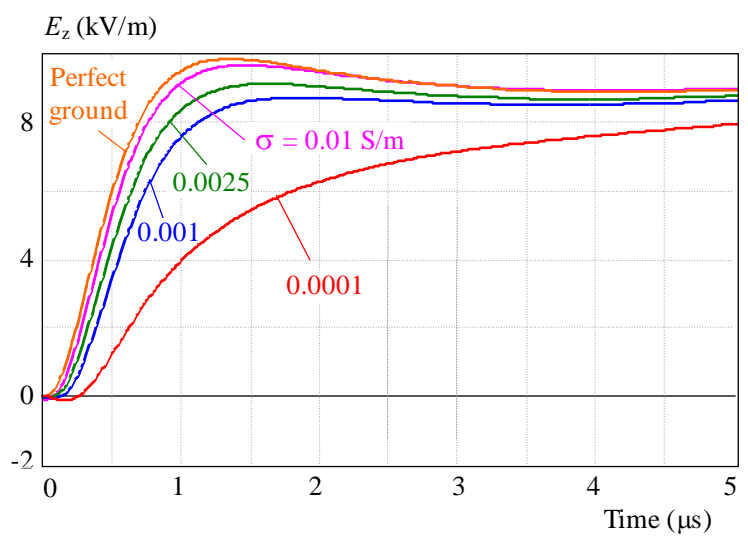

Fig. 7. Comparison of horizontal electric fields $r=50$,

$$
z=10 m, \varepsilon_{r}=10, \rho_{g}=0.1
$$

with $i_{g r} \equiv i_{g r}\left(h_{m, i}, t_{n}-\frac{R_{m}}{c}\right)$ and

$$
\begin{aligned}
& a_{m}=\left\{\begin{array}{l}
\frac{\Delta h_{i}}{2 k} \\
\frac{\Delta h_{i}}{k}
\end{array}, \quad a_{m}^{\prime}=\left\{\begin{array}{c}
\frac{\Delta h_{i}^{\prime}}{2 k} \\
\frac{\Delta h_{i}^{\prime}}{k}
\end{array}\right.\right. \\
& \text { for }\left\{\begin{array}{l}
m=1 \text { and } m=k+1 \\
\text { otherwise. }
\end{array}\right.
\end{aligned}
$$

On the other hand, the electric field components for a non-perfect ground conductivity condition can be evaluated by equations (6) and (7) for the horizontal and vertical electric fields, respectively whereby the Laplace transform, inverse Laplace transform to the time domain and the FDTD method are applied to the proposed electric field expression and the Cooray and Cooray-Rubinstein equations $[5,17,30-31]$.

$$
\begin{aligned}
& \left.\boldsymbol{E}_{r_{\mathrm{np}}}(r, z, t)\right|_{t=\sqrt{r^{2}+z^{2}} / c+n \Delta t}= \\
& \left.\sum_{j=1}^{n} \boldsymbol{H}_{\varphi}(r, z, t)\right|_{t=r / c+j \Delta t} S_{E r}(n-j+1)+ \\
& +\left.\boldsymbol{E}_{r}(r, z, t)\right|_{t=\sqrt{r^{2}+z^{2}} / c+n \Delta t} \\
& -\left.\sqrt{\frac{\mu_{0}}{\varepsilon}} \boldsymbol{H}_{\varphi}(r, z, t)\right|_{t=\sqrt{r^{2}+z^{2}} / c+n \Delta t}
\end{aligned}
$$

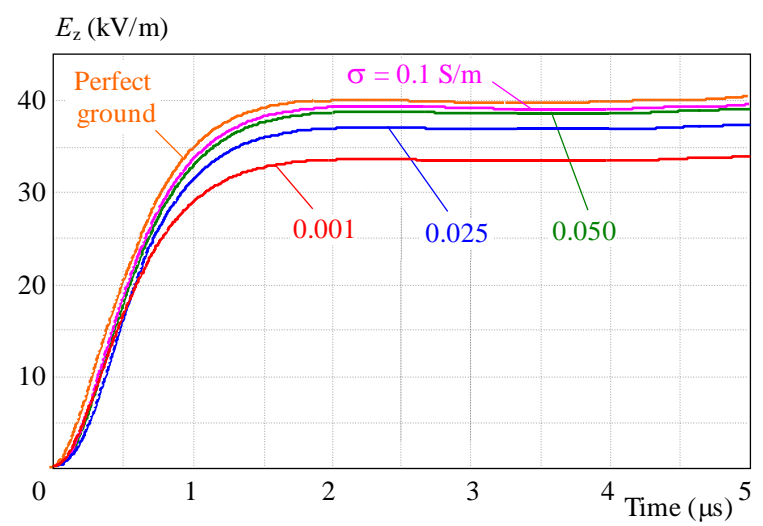

Fig. 6. Comparison of vertical electric fields $r=50, z=0$, $\varepsilon_{r}=10, \rho_{g}=0.1$

$$
\begin{aligned}
& \left.\boldsymbol{E}_{z_{\mathrm{np}}}(r, z, t)\right|_{t=\sqrt{r^{2}+z^{2}} / c+n \Delta t}= \\
& \left.\sum_{j=1}^{n} \boldsymbol{E}_{z}(r, z, t)\right|_{t=r / c+j \Delta t} S_{E z}(n-j+1)
\end{aligned}
$$

where $E_{r_{\mathrm{np}}}$ is the horizontal electric field in non perfect ground conductivity condition, $E_{z_{\mathrm{np}}}$ is the vertical electric field in non perfect ground conductivity condition, $\varepsilon_{r}$ is the relative dielectric constant, $\sigma$ is the conductivity of soil, and $\mu_{0}=4 \times 10^{-7} \mathrm{H} / \mathrm{m}$.

$$
\begin{gathered}
S_{m}(0, r, t)=\frac{\mathrm{d}}{\mathrm{d} t}\left(1-\exp \left(\frac{-t^{2}}{4 \eta^{2}}\right)+2 \alpha\left(\varepsilon_{r}+1\right) \frac{J(\chi)}{t}\right) \\
S_{n}(t)=-\sqrt{\frac{\mu_{0}}{\varepsilon}} \frac{\sigma}{2 \varepsilon} \exp \left(-\frac{\sigma}{2 \varepsilon} t\right)\left[I_{1}\left(\frac{\sigma}{2 \varepsilon}\right)-I_{0}\left(\frac{\sigma}{2 \varepsilon}\right)\right]
\end{gathered}
$$

where $I_{0}, I_{1}$ are modified Bessel functions and

$$
\begin{gathered}
\eta=\sqrt{\frac{r}{2 \mu_{0} \sigma c^{3}}}, \quad \alpha=\frac{1}{2 \mu_{0} \sigma c^{2}}, \quad \chi=\frac{t}{2 \eta} \\
J(\chi)=\chi^{2}\left(1-\chi^{2}\right) \\
S_{E z}(n-j+1)=\frac{\Delta t}{2}\left[\left.S_{m}(0, r, t)\right|_{t=(n-j) \Delta t}+\right. \\
\left.+\left.S_{m}(0, r, t)\right|_{t=(n-j+1) \Delta t}\right] \\
S_{E r}(n-j+1)=\frac{\Delta t}{2}\left[\left.S_{n}(t)\right|_{t=(n-j) \Delta t}+\right. \\
\left.+\left.S_{n}(t)\right|_{t=(n-j+1) \Delta t}\right] \\
4 \text { RESULT AND DISCUSSION }
\end{gathered}
$$

\section{RESULT AND DISCUSSION}

Figure 5 shows a comparison between the simulated vertical electric field and the corresponding measured field based on the current parameters from table 1 at an 
observation point $30 \mathrm{~m}$ distant from the lightning channel which shows the simulated field is in good agreement with the measured field. It should be mentioned that the measured field is obtained from a triggered lightning experiment and the field sensor is located on the surface of the ground.

Figure 6 illustrates the effect of ground conductivity on the values of the electric fields based on the proposed field expressions. This figure shows that the ground conductivity has an effect on the peak value of the vertical electric field and demonstrates that the peak field due to the lightning channel with reflection has an inverse relationship with the value of the ground conductivity. Therefore, the value of the evaluated vertical electric field is due to a combination of three effects $i e$ the original current, the reflected current and the ground conductivity effect. It is noted that the vertical electric field is an important parameter in some coupling models to evaluate the lightning induced voltage on power lines.

Moreover, Fig.7 illustrates the behaviour of the simulated horizontal electric fields based on the proposed field expressions versus different values of the ground conductivity which shows the ground conductivity has an effect on the peak value and the rise time of the horizontal electric field. Likewise, it demonstrates that the peak value of the field has a direct relationship with the ground conductivity value. It can be observed that the horizontal electric field is an effective parameter in the Agrawal[1, 3,32 ] coupling model to estimate lightning induced voltages on the power line.

The proposed method can support the widely used current functions and models directly in the time domain without the need to apply any extra conversions and it can also evaluate the electric field components due to the lightning channel by considering the ground reflection factor as well as the effect of ground conductivity on the fields. The proposed field expressions can be combined with the widely used coupling models such as the Taylor[33-34] and Agrawal[1, 32] models to evaluate the lightning induced voltage directly in the time domain and for setting the appropriate protection level for the power lines as the expressions can take into account the effects of ground reflection and ground conductivity.

\section{CONCLUSION}

In this paper, analytical lightning electric field expressions are proposed to consider the ground reflection at the channel base and the ground conductivity condition directly in the time domain. The proposed method can support the common current models and functions without the need to apply any extra conversions. The results show that the ground conductivity and ground reflection have an effect on the peak and shape of the electric field components. The electric field components are applicable to the widely used common coupling models and by considering them this can be useful for setting the appropriate protection level for the power lines.

\section{REFERENCES}

[1] PAOLONE, M.-NUCCI, C.-RACHIDI, F. : A new finite difference time domain scheme for the evaluation of lightning induced overvoltage on multiconductor overhead lines.

[2] PAOlOne, M.-NUCCI, C.-PETRACHE, E.-RACHIDI, F.: Mitigation of lightning-induced overvoltages in medium voltage distribution lines by means of periodical grounding of shielding wires and of surge arresters: Modeling and experimental validation, IEEE Transactions on Power Delivery 19 (2004), 423-431.

[3] NUCCI, C. A.-RACHIDI, F.-IANOZ, M.-MAZZETTI, C. : Lightning-induced voltages on overhead lines, IEEE Transactions on Electromagnetic Compatibility 35 (1993), 75-86.

[4] NUCCI, C. A.: Lightning-induced voltages on overhead power lines, Part I: Return stroke current models with specified channel-base current for the evaluation of the return stroke electromagnetic fields, Electra 161 (1995), 75102.

[5] IZADI, M.-KADIR, M.: New Algorithm for Evaluation of Electric Fields due to Indirect Lightning Strike, CMES: Computer Modeling in Engineering \& Sciences 67 (2010), 1-12.

[6] IZADI, M.-ABKADIR, M. Z.-GOMES, C-WANAHMAD, W.: An Analytical Second-FDTD Method For Evaluation of Electric and Magnetic Fields at Intermediate Distances From Lightning Channel, Progress In Electromagnetic Research (PIER); 110 (2010), 329-352.

[7] IZADI, M.-ABKADIR, M. Z.-GOMES, C.-WANAHMAD, W. : Evaluation of electromagnetic fields due to lightning channel with respect to the striking angle, International Review of Electrical Engineering (IREE) 6 (2011), 1013-1023.

[8] IZADI, M.-ABKADIR, M. Z.-ABIDIN, M. Z.-GOMES, C. : Evaluation of Electromagnetic Fields Associated with Inclined Lightning Channel Using Second Order FDTD-Hybrid Methods, Progress In Electromagnetics Research 117 (2011), 209-236.

[9] IZADI, M.-KADIR, M. Z. A. A.-GOMES, C.-AHMAD, W. F. W.: Numerical expressions in time domain for electromagnetic fields due to lightning channels', International Journal of Applied Electromagnetics and Mechanics 37 (2011), 275-289.

10] THOTTAPPILLIL, R.-RAKOV, V.: Review of three equivalent approaches for computing electromagnetic fields from an extending lightning discharge, Journal of Lightning Research 1 (2007), 90-110.

[11] THOTTAPPILliL, R-RAKOV, V.-UMAN, M.: Distribution of charge along the lightning channel: Relation to remote electric and magnetic fields and to return-stroke models, Journal of Geophysical Research 102 (1997), 6987-7006.

[12] UMAN, M. A.-MCLAIN, D. K.: Magnetic field of lightning return stroke, Journal of Geophysical Research 74 (1969), 6899-6910.

[13] MOINI, R.-SADEGHI, S.-KORDI, B.-RACHIDI, F.: An antenna-theory approach for modeling inclined lightning return stroke channels, Electric power systems research 76 (2006), 945-952.

[14] MOINI, R.-RAKOV, V.-UMAN, M.-KORDI, B. : An antenna theory model for the lightning return stroke, Time (1997), $149-152$.

[15] IZADI, M.-KADIR, Z. A. A. M-GOMES, C. : On the consideration of the channel angle effects on the electromagnetic fields associated with inclined lightning channel, in Power Engineering and Optimization Conference (PEOCO) 2012 IEEE International (2012), 153-158.

[16] IZADI, M.-ABKADIR, M. Z.-GOMES, C.-AHMAD, W. F. H. W.: Analytical Expressions for Electromagnetic Fields Associated with the Inclined Lightning Channels in the Time Domain, Electric Power Components and Systems 40 (2012), $414-438$. 
[17] V. COORAY: The lightning flash: IET Press.

[18] RUBINSTEIN, M.: An approximate formula for the calculation of the horizontal electric field from lightning at close, intermediate, and longrange, IEEE Transactions on Electromagnetic Compatibility 38 (1996), 531-535.

[19] IZADI, M.-KADIR, M.-AHMAD, W.-NAWI, Z.-ASKARI, M.: On comparison between Cooray-Rubinstein and FDTD methods for ground conductivity effect on horizontal electric field evaluation in time domain, Research and Development (SCOReD) 2009 IEEE Student Conference, 336-340.

[20] IZADI, M.-KADIR, M. Z. A-GOMES, C-ASKARI, M. T. : Evaluation of lightning return stroke parameters using measured magnetic flux density and pso algorithm, PRZEGLD ELEKTROTECHNICZNY (Electrical Review) R. 88 NR 10a (2012).

[21] IZADI, M.-ABKADIR, M. Z. A.-GOMES, C.-COORAY, V.-SHOENE, J.: Evaluation of lightning current and velocity profiles along lightning channel using measured magnetic flux density, Progress In Electromagnetics Research (PIER) 130 (2012), 473-492.

[22] IZADI, M.-ABKADIR, M. Z. A.-GOMES, C.-COORAY, V.: Evaluation of lightning return stroke current using measured electromagnetic fields, Progress In Electromagnetics Research (PIER); 130 (2012), 581-600.

[23] HEIDLER, F.: Analytische Blitzstromfunktion zur LEMPBerechnung, presented at the 18th ICLP Munich, Germany (1985).

[24] ANDREOTTI, A.-DELFINO, F.-GIRDINIO, P.-VEROLINO L.: An identification procedure for lightning return strokes, Journal of Electrostatics 51 (2001), 326-332.

[25] ANDREOTTI, A.-DELFINO, F.-GIRDINIO, P.-VEROLINO L. : A field-based inverse algorithm for the identification of different height lightning return strokes, The International Journal for Computation and Mathematics in Electrical and Electronic Engineering(COMPEL) 20 (2001), 724-731.

[26] IZADI, M.-KADIR, M. : Considering on charge density along return stroke lightning channel, in Power and Energy (PECon) 2010 IEEE International Conference (2010), 384-389.

[27] RAKOV, V.: Lightning electromagnetic fields: Modeling and measurements, in 12th Int. Zurich Symposium on Electromagnetic Compatibility Zurich, Switzerland (1997), 59-64.

[28] BERMUDEZ, J. L.: Lightning currents and electromagnetic fields associated with return strokes to evaluated strike objects, Phd Ecole Polytechnique Federale De Lausanne (2003).

[29] RAKOV, V. : lightning return stroke speed, Journal of lightning Research 1 (2007).

[30] KREYSZIG, E.: Advanced engineering mathematics, Wiley-India (2007).

[31] SADIKU, M.: Numerical technique in electromagnetics, CRC Press LLC (2001).
[32] NUCCI, C. A.: Lightning-induced voltages on overhead power lines. Part II: Coupling models for the evaluation of the induced voltages, Electra 162 (1995), 121145.

[33] M. IZADI-M. Z. A. ABKADIR-F. A. A. RAHMAN : On Comparison between Rusck and Taylor Coupling Models for Evaluation of Lightning Induced Voltage on the Power Lines, Asia Pacific Symposium of Applied Electromagnetics and Mechanics (APSAEM2010) (2010).

[34] ANDREOTTI-MOTTOLA-PAGANO_VEROLINO: An Exact Closed From Solution for Lightning Induced Over voltage Calculation, IEEE Transactions on Power Delivery 24 (2009).

Received 20 September 2012

Mahdi Izadi (Dr) was born in Tehran, Iran, in 1977. He received BSc in electrical power engineering from Azad University, Iran at 1999 and obtained MSc and PhD degrees in electrical power engineering from University Putra Malaysia (UPM), Malaysia at 2010 and 2012, respectively. Currently, he is a researcher in the CELP center, Department of Electrical and Electronics Engineering, Faculty of Engineering, University Putra Malaysia. He has authored and co-authored more than 30 scientific papers published in journals and conferences. His research interests include lightning effects on the power , systems and lightning electromagnetic fields and protection of power systems.

M. Z. A. Ab Kadir (Prof) graduated with BEng degree in Electrical and Electronic from University Putra Malaysia in 2000 and obtained his PhD from the University of Manchester, United Kingdom in 2006 in High Voltage Engineering. Currently, he is an Associate Professor in the Department of Electrical and Electronics Engineering, Faculty of Engineering, University Putra Malaysia. To date he has authored and co-authored over 60 technical papers comprising of national and international conferences proceedings and citation indexed journals. His research interests include high voltage engineering, insulation coordination, lightning protection, EMC/EMI and power system transients.

Maryam Hajikhani was born in Tehran, Iran at 1978. She graduated BSc and MSc in computer engineering from Azad University, Iran and MMU University, Malaysia at 2003 and 2011, respectively. She is currently pursuing his $\mathrm{PhD}$ in UPM and she has authored and co-authored more than 3 scientific papers published in journals and conferences. Her interests include algorithms and computer coding. 